\title{
Surfactin Facilitates Horizontal Gene Transfer in Bacillus subtilis
}

OPEN ACCESS

Edited by:

Jörg Stülke,

University of Göttingen, Germany

Reviewed by:

Oscar P. Kuipers,

University of Groningen, Netherlands Berenike Maier,

University of Cologne, Germany

*Correspondence: Tjaša Danevčič

tjasa.danevcic@bf.uni-lj.si Ines Mandic-Mulec

ines.mandicmulec@bf.uni-lj.si

Specialty section:

This article was submitted to Microbial Physiology and Metabolism, a section of the journal

Frontiers in Microbiology

Received: 22 January 2021 Accepted: 07 April 2021 Published: 14 May 2021

Citation:

Danevčič T, Dragoš $A$ Spacapan M, Stefanic P, Dogsa I and Mandic-Mulec I (2021) Surfactin Facilitates Horizontal Gene Transfer in Bacillus subtilis.

Front. Microbiol. 12:657407. doi: 10.3389/fmicb.2021.657407

\section{Tjaša Danevčičc*, Anna Dragoš ${ }^{1,2}$, Mihael Spacapan1, Polonca Stefanic ${ }^{1}$, Iztok Dogsa $^{1}$ and Ines Mandic-Mulec ${ }^{1 *}$}

${ }^{1}$ Chair of Microbiology, Department of Food Science and Technology, Biotechnical Faculty, University of Ljubljana, Ljubljana, Slovenia, ${ }^{2}$ Bacterial Interactions and Evolution Group, Department of Biotechnology and Biomedicine, Technical University of Denmark, Kongens Lyngby, Denmark

Genetic competence for the uptake and integration of extracellular DNA is a key process in horizontal gene transfer (HGT), one of the most powerful forces driving the evolution of bacteria. In several species, development of genetic competence is coupled with cell lysis. Using Bacillus subtilis as a model bacterium, we studied the role of surfactin, a powerful biosurfactant and antimicrobial lipopeptide, in genetic transformation. We showed that surfactin itself promotes cell lysis and DNA release, thereby promoting HGT. These results, therefore, provide evidence for a fundamental mechanism involved in HGT and significantly increase our understanding of the spreading of antibiotic resistance genes and diversification of microbial communities in the environment.

Keywords: quorum sensing, competence, surfactin, DNA exchange, extracellular DNA, cell lysis, horizontal gene transfer

\section{INTRODUCTION}

Surfactin is an important microbial surfactant with interesting biological activities. It is important for social spreading on solid surfaces (Kearns and Losick, 2003; Kinsinger et al., 2003; Grau et al., 2015; van Gestel et al., 2015), rhizosphere colonization (Bais et al., 2004; Aleti et al., 2016), biocontrol of a plant pathogen (Bais et al., 2004), or potentially even human viruses (Yuan et al., 2018). Its synthesis is regulated by a process called quorum sensing (QS) (Roggiani and Dubnau, 1993). In the Gram-positive bacterium Bacillus subtilis, the major QS system ComQXPA activates the transcription of hundreds of genes, including the srfA operon and competence genes (Weinrauch et al., 1990; Roggiani and Dubnau, 1993; Magnuson et al., 1994). The srfA operon encodes enzymes for the synthesis of surfactin and also contributes to the development of genetic competence (D'Souza et al., 1994; Hamoen et al., 2003; Comella and Grossman, 2005) through a small out-of-frame gene, comS, that is embedded in the second gene ( $s r f A B)$ of the operon (Nakano et al., 1991; D'Souza et al., 1994; Hamoen et al., 2003; Comella and Grossman, 2005). ComS stops proteolytic degradation of ComK (Turgay et al., 1998) that then increases in concentration and consequently activates the transcription of late competence genes that encode processes responsible for the DNA uptake and integration (Dubnau, 1991). This state has been referred to as the K-state (Berka et al., 2002). Therefore, surfactin is linked to competence development because phosphorylated ComA (ComA-P) de-represses the srfA operon, which ultimately stabilizes ComK and the K-state, thereby increasing the transformation frequency of the population (Miras and Dubnau, 2016). Competence and transformation of Bacillus subtilis is a result of a complex regulatory network that, through stochastic cell differentiation, occurs only in 10-20\% 
of the cells within a population and is transient (approximately $2 \mathrm{~h}$ ) in nature (reviewed by Maier, 2020). It has been shown previously that in $B$. subtilis PS-216, competence is developed in the late exponential growth phase (Miras and Dubnau, 2016), when surfactin production is high (Oslizlo et al., 2014; Dogsa et al., 2021). Both ComA and the srfA de-repression, therefore, have significant effects on HGT, which shapes microbial evolution and ecology. Transformation also requires extracellular DNA (eDNA), which is spontaneously released by $B$. subtilis during growth (Zafra et al., 2012) through a mechanism that is not yet fully understood.

The aim of this study was to investigate the role of surfactin in eDNA release and genetic transformation. This is of fundamental importance as transformation mediates horizontal gene transfer and potentially contributes to dissemination of antibiotic resistance and diversification of microbial communities.

\section{MATERIALS AND METHODS}

\section{Bacterial Strains and Growth Conditions}

Bacterial strains used in this study are listed in Table 1. Overnight cultures were incubated in liquid lysogeny broth (LB) with the appropriate antibiotics at $37^{\circ} \mathrm{C}$ and $200 \mathrm{rpm}$. The concentrations of antibiotics were as follows: chloramphenicol (Cat) $10 \mu \mathrm{g} \mathrm{ml}^{-1}$, spectinomycin (Spec) $100 \mu \mathrm{g} \mathrm{ml} \mathrm{m}^{-1}$, kanamycin (Kn) $50 \mu \mathrm{g}$ $\mathrm{ml}^{-1}$, erythromycin (Ery) $0.5 \mu \mathrm{g} \mathrm{ml}^{-1}$, lincomycin (Lin) $12.5 \mu \mathrm{g}$ $\mathrm{ml}^{-1}$, and ampicillin (Amp) $100 \mu \mathrm{g} \mathrm{ml}^{-1}$. Growth of B. subtilis strains was assessed by measuring optical density at $650 \mathrm{~nm}$
$\left(\mathrm{OD}_{650}\right)$ following inoculation of fresh $\mathrm{CM}$ medium (Albano et al., 1987) with an overnight culture (1\%, V/V) and incubation at $37^{\circ} \mathrm{C}$ and $200 \mathrm{rpm}$.

\section{Strain Construction}

Mutant strains were constructed by transformation of specific markers into competent B. subtilis strains. Strains were grown in $\mathrm{CM}$ medium at $37^{\circ} \mathrm{C}$ and $200 \mathrm{rpm}$, and transformants were selected by antibiotic selections on LB agar plates with the appropriate antibiotics at $37^{\circ} \mathrm{C}$. The $\Delta \cot A, \Delta s k f A$, and $\Delta s r f A$ mutants were constructed by transforming appropriate $B$. subtilis strains with chromosomal DNA isolated from B. subtilis RL50 (Donovan et al., 1987), EG165 (Liu et al., 2010), or OKB120 (Nakano et al., 1988), respectively. The amyE: $\mathrm{P}_{43}$-lacZ mutants were constructed by transforming appropriate B. subtilis strains with plasmid DNA pEM1055.

To construct pEM1055 plasmid, carrying amyE: $\mathrm{P}_{43}$-lacZ, a constitutive promoter $\mathrm{P}_{43}$ was PCR-amplified from plasmid DNA Pkm3-p43-yfp (Stefanic et al., 2015) using the primer pair p43F1-EcoRI/p43-R1-BamHI (Table 2). The PCR fragment was then digested with EcoRI and BamHI and ligated into EcoRI and BamHI sites of pBKT2 (Meijer et al., 1995). The constructed plasmid was then transformed into competent $E$. coli $\mathrm{DH} 5 \alpha$ cells, and transformants were selected on LB agar plates containing $100 \mu \mathrm{g} \mathrm{ml}^{-1}$ Amp after overnight incubation at $37^{\circ} \mathrm{C}$. Plasmids were isolated and screened by PCR using the same primer pair listed above to determine if the cells carried the amyE: $\mathrm{P}_{43}-l a c Z$ construct before transformation in B. subtilis strains.

TABLE 1 | Strains used in this study.

\begin{tabular}{|c|c|c|c|c|}
\hline Strain name & Descriptive & Background & Genome description & References \\
\hline \multicolumn{5}{|c|}{ Bacillus subtilis strains } \\
\hline PS-216 & wt & & Undomesticated strain & Stefanic and Mandic-Mulec, 2009 \\
\hline BM1060 & $w^{\text {cat }}$ & PS-216 & $\operatorname{cotA}:$ cat & This work \\
\hline BM1058 & $w t^{\text {spec }}$ & PS-216 & $\Delta s k f A: s p e c$ & This work \\
\hline BM1044 & $\Delta s r f A$ & PS-216 & srfA:Tn917 (mls) & This work \\
\hline BM1062 & $\Delta s r f A^{\text {cat }}$ & PS-216 & srfA:Tn917 (mls) cotA:cat & This work \\
\hline BM1063 & $\Delta s r f A^{\text {spec }}$ & PS-216 & srfA:Tn917 (mls) $\Delta$ skfA:spec & This work \\
\hline BM1298 & wt $^{\text {lacZ }}$ & PS-216 & amyE:P $\mathrm{P}_{43}-\mathrm{lac} Z(\mathrm{Kn})$ & This work \\
\hline BM1299 & $\Delta s r f A^{\text {lacZ }}$ & PS-216 & srfA:Tn917 (mls) amyE:P43-lacZ (Kn) & This work \\
\hline BM1097 & & PS-216 & amyE:Phyperspank $-m K a t e 2(\mathrm{Cm})$ & Stefanic et al., 2015 \\
\hline RL50 & & PY17 & $\operatorname{trp} C 2 \cot A: c a t$ & Donovan et al., 1987 \\
\hline EG165 & & PY79 & $\Delta s k f A: s p e c$ & Liu et al., 2010 \\
\hline OKB120 & & 168 & pheA1 sfp sifA:Tn917 (mls) & Nakano et al., 1988 \\
\hline \multicolumn{5}{|c|}{ Escherichia coli strains } \\
\hline EM1070 & Pkm3-p43-YFP & $\mathrm{DH} 5 \alpha$ & amyE:P $43-y f p($ Spec, Amp) & Stefanic et al., 2015 \\
\hline EM1054 & pBTK2 & $\mathrm{DH} 5 \alpha$ & pBKT2 amyE:lacZ (Kn, Amp) & Meijer et al., 1995 \\
\hline EM1055 & pEM1055 & $\mathrm{DH} 5 \alpha$ & pBKT2 amyE:P43-lacZ (Kn, Amp) & This work \\
\hline
\end{tabular}

TABLE 2 | Oligonucleotides used in this study.

\begin{tabular}{|c|c|c|}
\hline Oligonucleotide name & Sequence $5^{\prime}-3^{\prime}$ & References \\
\hline $\mathrm{p} 43-\mathrm{F} 1-E \mathrm{C} O \mathrm{Rl}$ & CGCGAATTCTGATAGGTGGTATGTITCGCTTG & Stefanic et al., 2015 \\
\hline p43-R1-BamHI & GCGGGATCCCCTATAATGGTACCGCTATCAC & This work \\
\hline
\end{tabular}




\section{Transformation Frequency Determination}

Overnight cultures $(1 \%, V / V)$ were inoculated into the fresh $\mathrm{CM}$ medium, and cells were grown at $37^{\circ} \mathrm{C}$ and $200 \mathrm{rpm}$ for $6 \mathrm{~h}$. After incubation, $1 \mathrm{ml}$ of the culture was transferred to a glass tube and supplemented with genomic DNA of B. subtilis PS-216 amyE: $\mathrm{P}_{\text {hyperspank }}-m K a t e 2$ carrying chloramphenicol resistance (final saturating concentration $1.4 \mu \mathrm{g} \mathrm{ml}^{-1}$ ) (Stefanic et al., 2015). Tubes were incubated for $30 \mathrm{~min}$ at $37^{\circ} \mathrm{C}$ and $200 \mathrm{rpm}$. Fresh LB medium $(0.5 \mathrm{ml})$ was then added, and samples were incubated for a further $60 \mathrm{~min}$ at $37^{\circ} \mathrm{C}$ and $200 \mathrm{rpm}$. Finally, $100 \mu \mathrm{l}$ of sample dilutions $\left(10^{0}, 10^{-1}, 10^{-2}\right)$ were inoculated onto LB agar containing $10 \mu \mathrm{g} \mathrm{ml}^{-1}$ of Cat. In addition, a control experiment without DNA added was performed. Viable cell concentration was determined by standard CFU assay on LB agar plates without antibiotics. Transformation frequency was calculated as the ratio between the number of transformants and the viable cell number.

\section{Transformation Frequency Determination in Co-culture}

Two B. subtilis strains carrying different antibiotic markers (cat or spec) integrated at different chromosomal loci in each strain were co-cultured. The co-culture approach enabled us to directly select for transformants with double resistance. Starting ratios of $\mathrm{Cat}^{\mathrm{R}}$ strain and $\mathrm{Spec}^{\mathrm{R}}$ strain (1:1) were prepared based on $\mathrm{OD}_{650}$ estimation of overnight cultures. Co-cultures were incubated in CM medium without or with surfactin $(20 \mu \mathrm{g}$ $\left.\mathrm{ml}^{-1}\right)$ and without or with DNase I (100 U) for $8 \mathrm{~h}$ at $37^{\circ} \mathrm{C}$ and $200 \mathrm{rpm}$, which allowed spontaneous integration of cat or spec antibiotic markers into Spec ${ }^{\mathrm{R}}$ or $\mathrm{Cat}^{\mathrm{R}}$ strains, respectively. After incubation, $100 \mu \mathrm{l}$ of co-culture dilutions $\left(10^{0}, 10^{-1}, 10^{-2}\right)$ were plated onto LB agar plates containing two antibiotics, Cat $\left(5 \mu \mathrm{g} \mathrm{ml}^{-1}\right)$ and Spec $\left(50 \mu \mathrm{g} \mathrm{ml}^{-1}\right)$. Viable cell number in co-cultures was determined by standard CFU assay on LB agar without antibiotics. Transformation frequency in co-culture was calculated as a ratio of the number of transformants with both antibiotic markers and viable cell number.

\section{Influence of Surfactin on Growth and eDNA Release}

Fresh CM medium was inoculated with an overnight culture $(1 \%, \mathrm{~V} / \mathrm{V})$ of the $\Delta s r f A$ mutant and incubated at $37^{\circ} \mathrm{C}$ and $200 \mathrm{rpm}$ for $8 \mathrm{~h}$. CM medium was supplemented with different surfactin concentrations $\left(2.5,5,10,15\right.$, and $\left.20 \mu \mathrm{g} \mathrm{ml}^{-1}\right)$. As controls, the wild-type strain and $\triangle$ srfA mutant were grown in the same conditions without surfactin addition. After incubation, cultures were centrifuged at $10,000 \times g$ for $10 \mathrm{~min}$, supernatants were filter sterilized, and eDNA concentration was determined. In addition, viable cell number was determined as described above.

\section{Time of Exposure to Surfactin}

Fresh CM medium was inoculated with an overnight culture $(1 \%, \mathrm{~V} / \mathrm{V})$ of the $\mathrm{wt}^{\text {lacZ }}$ or $\Delta s r f A^{\text {lacZ }}$ strain, and cultures were grown to an early stationary phase at $37^{\circ} \mathrm{C}$ and $200 \mathrm{rpm}$. Cultures were then supplemented with $20 \mu \mathrm{g} \mathrm{ml}^{-1}$ of surfactin and incubated for a further $3 \mathrm{~h}$ at room temperature without shaking.
At different times of exposure to surfactin $(0,20,40,80$, and $160 \mathrm{~min}$ ), $\beta$-galactosidase activity and eDNA concentrations were measured in filter-sterilized conditioned medium of both strains, and viable cell number was determined as described above.

\section{$\beta$-Galactosidase Activity Measurement}

Z-buffer $\left(36 \mathrm{mM} \mathrm{NaH} 2 \mathrm{PO}_{4}, 67 \mathrm{mM} \mathrm{NaHPO}_{4}, 0.1 \mathrm{mM}\right.$ $\left.\mathrm{MgCl}_{2}, 2 \mathrm{mM} \mathrm{MgSO} 4\right)(25 \mu \mathrm{l})$ containing $5.6 \%(\mathrm{~V} / \mathrm{V})$ of $\beta$-mercaptoethanol and $10 \mu \mathrm{l}$ toluene was added to the conditioned media of the wt ${ }^{\text {lacZ }}$ and $\Delta s r f A^{\text {lacZ }}$ strains in a microtiter plate, and the plate was incubated on ice for $30 \mathrm{~min}$. The plate was then warmed to $30^{\circ} \mathrm{C}$, then $50 \mu \mathrm{l}$ of orthonitrophenyl- $\beta$-galactoside (ONPG) substrate was added, and the absorbance at $420 \mathrm{~nm}$ was measured during incubation for $15 \mathrm{~min}$ at 1 -min intervals at $30^{\circ} \mathrm{C}$ using Multiscan Spectrum (Thermo Scientific). $\mathrm{OD}_{650}$ and ONPG degradation rate was used to calculate $\beta$-galactosidase activity.

\section{Extracellular DNA (eDNA) Concentration Determination}

Extracellular DNA concentration in filter-sterilized conditioned media of the wild-type strain, $\Delta s r f A$ strains following addition of different surfactin concentrations, and the wt ${ }^{\text {lac } Z}$ and $\Delta s r f A^{\text {lacZ }}$ strains and co-cultures was determined using QuantiFluor ${ }^{\circledR}$ dsDNA system (Promega, United States) by measuring fluorescence intensity according to the manufacturer's instructions. The excitation and emission wavelengths were set to 504 and $531 \mathrm{~nm}$, respectively, and the gain was set to 100 . A standard curve was prepared using the Lambda DNA standard provided with the kit. eDNA concentration was calculated by subtracting fluorescence intensity of an uninoculated growth medium (containing yeast extract) from fluorescence intensity of samples of conditioned media.

\section{Statistical Analysis}

All data are presented as means and standard errors of biological replicates. Results were statistically evaluated using one-way ANOVA followed by Bonferroni's post hoc comparisons tests using the $p \leq 0.05$ level of significance.

\section{RESULTS}

\section{Genetic Transformation via DNA Exchange}

Genetic transformation is mostly studied in monocultures to which extracellular DNA with an antibiotic resistance locus is added, and transformants are selected on LB agar plates containing this antibiotic (Figure 1A). However, in a natural setting, DNA is usually released by cells that undergo lysis or actively release DNA (reviewed in Ibáñez de Aldecoa et al., 2017), which could be captured by cells in the vicinity (Steinmoen et al., 2002; Veening and Blokesch, 2017). This assumption was tested by mixing two $B$. subtilis PS-216 strains, which carry different antibiotic markers (chloramphenicol or spectinomycin resistance cassettes/cat or spec) integrated at different chromosomal loci, at 
A DNA transformation with added DNA
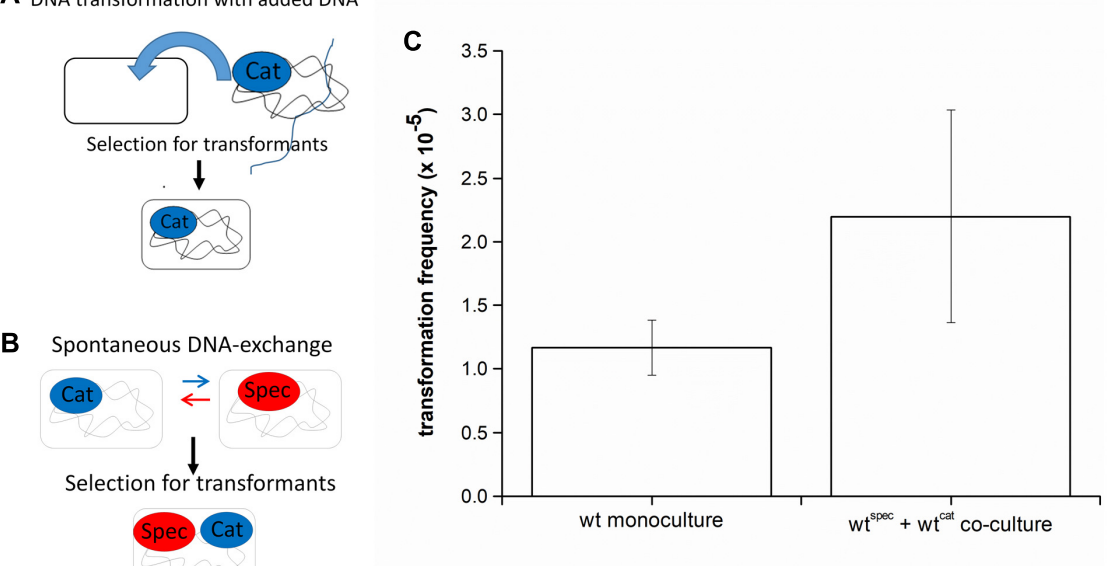

FIGURE 1 | (A) A schematic representation of the transformation assay with added DNA. Bacillus subtilis strain was grown in monoculture in CM medium for $6 \mathrm{~h}$ at $37^{\circ} \mathrm{C}$ and $200 \mathrm{rpm}$ and then genomic DNA carrying an antibiotic resistance marker (chloramphenicol-Cat ${ }^{\mathrm{R}}$ ) was added to the medium. This enabled cells to receive DNA and provided an opportunity to develop resistance to antibiotic (Cat-Cat ${ }^{\mathrm{R}}$ ). (B) A schematic representation of the DNA exchange assay. Two B. subtilis strains, each carrying a different antibiotic resistance marker (chloramphenicol-Cat ${ }^{R}$ or spectinomycin-Spec ${ }^{R}$ ) were grown in co-culture in $\mathrm{CM}$ medium for $8 \mathrm{~h}$ at $37^{\circ} \mathrm{C}$ and $200 \mathrm{rpm}$. This enabled spontaneous DNA exchange between the two strains and provided an opportunity to develop resistance to both antibiotics (Cat and Spec-Cat ${ }^{R}$ Spec $^{R}$ ). (C) Transformation frequency of Bacillus subtilis PS-216 wild-type strain in monoculture and in co-culture grown in CM medium. The values presented are means and standard errors $(n=3)$.

1:1 ratio. After the indicated incubation time, transformants were selected by plating the co-culture directly on LB agar plates with both antibiotics (Figure 1B). We refer to this process as DNA exchange because both single-antibiotic resistance strains have a comparable chance to acquire the resistance gene of the second antibiotic, thereby becoming double-antibiotic resistant. The results show that transformation frequency by DNA exchange is high $\left[(2.2 \pm 0.84) \times 10^{-5}\right]$. If the standard transformation assay was carried out by adding the saturating concentration of DNA to PS-216 monoculture, the detected transformation frequency was $(1.17 \pm 0.22) \times 10^{-5}$ (Figure 1C). Next, it was tested whether DNA exchange is mediated by transformation by adding DNase $\mathrm{I}(100 \mathrm{U})$ to the co-culture and again selecting transformants for $\mathrm{Cat}^{\mathrm{R}} \mathrm{Spec}^{\mathrm{R}}$ double resistance. DNA exchange of PS-216 wild-type strains in co-culture was completely abolished in the presence of DNase I. The fact that we could not detect any transformants in the presence of DNase I indicates that DNA exchange is mediated by free DNA and not horizontal gene transfer vesicles.

\section{Surfactin Promotes DNA Release and Facilitates Intraspecies DNA Exchange}

It is already known that B. subtilis NCIB 3610 secretes high molecular weight DNA during growth (Zafra et al., 2012) and that $B$. subtilis strains with a deletion in the surfactin operon (B. subtilis NCIB $3610 \triangle s r f A A$ ) are impaired in DNA release (Zafra et al., 2012). However, whether surfactin may have a direct or indirect role in this process has not been tested directly. To determine the relationship between surfactin concentration and DNA release, the $\triangle \operatorname{srfA}$ mutant (BM1044) was incubated with different concentrations of surfactin (2.5-20 $\left.\mu \mathrm{g} \mathrm{ml}^{-1}\right)$ and eDNA concentration was compared with that released by the wild-type strain. eDNA concentration in the conditioned medium of the $\triangle s r f A$ mutant strain was approximately 15 -fold lower than that in the conditioned medium of the wild-type strain (Figure 2A). We also observed that levels of eDNA released by the $\Delta s r f A$ mutant could be restored by the addition of surfactin to the growth medium, in a concentration-dependent manner (Figure 2A). The maximal surfactin concentration $\left(20 \mu \mathrm{g} \mathrm{ml}^{-1}\right)$ recovered the phenotype of the surfactin mutant to the levels of the surfactin producing wild-type strain. This surfactin concentration was previously measured in the spent media of B. subtilis PS-216 during early stationary phase (Oslizlo et al., 2014). It is known that when the surfactin concentration is below or near the critical micelle concentration (10-25 $\mu \mathrm{g} \mathrm{ml}^{-1}$ ) surfactin inserts into phospholipid layers inducing mild content leakage. On the other hand, at higher concentrations, surfactin attacks the phospholipid bilayer causing membrane solubilization (Deleu et al., 2013). The influence of surfactin concentration on final colony-forming units (CFU) was determined for a $\triangle s r f A$ mutant where CFU count did not decrease significantly with increasing surfactin concentration (Figure 2B). These results, therefore, indicated that surfactin promotes eDNA release, either through active release that might limit cell growth (although this is not easily detectable) or through cell lysis.

To further investigate whether cell lysis is responsible for eDNA release, levels of extracellular $\beta$-galactosidase in the conditioned medium of $\mathrm{wt}^{\text {lacZ }}(\mathrm{BM} 1298)$ or $\Delta s r f A^{\text {lacZ }}$ (BM1299) cultures were measured after incubation with surfactin (Figure 3A). $\beta$-galactosidase is localized intracellularly, and its presence in the culture supernatant is generally used as a measure of bacterial cell lysis (Steinmoen et al., 2002; Zafra et al., 2012). Early stationary phase cultures of the wt ${ }^{\text {lacZ }}$ and $\Delta s r f A^{\text {lacZ }}$ strains were exposed to surfactin $\left(20 \mu \mathrm{g} \mathrm{ml}^{-1}\right.$ in CM medium), 


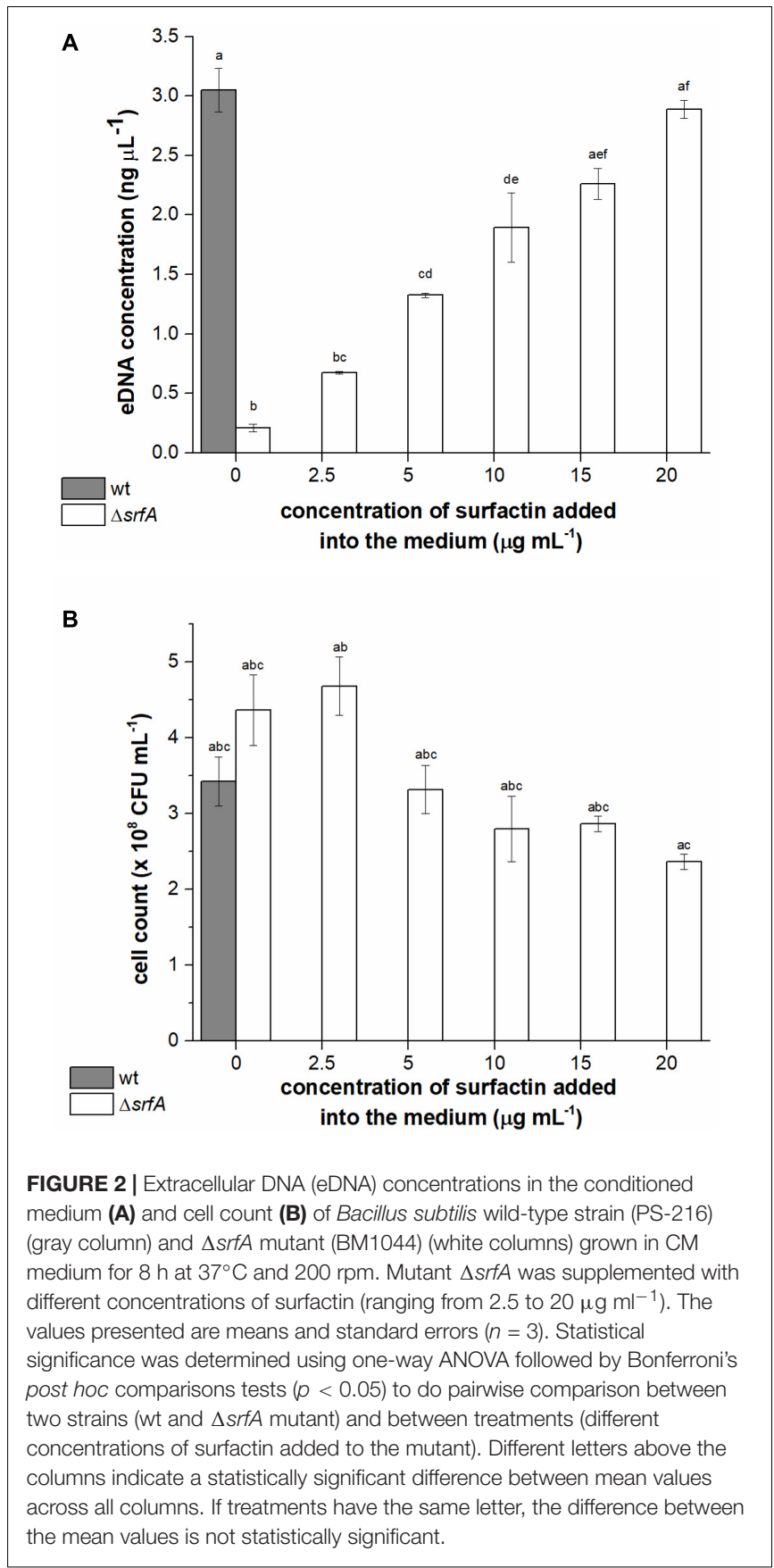

and CFU, eDNA concentration, and extracellular $\beta$-galactosidase activity were measured after exposure to surfactin for 0 $3 \mathrm{~h}$ (Figure 3). Extracellular $\beta$-galactosidase activity in $\mathrm{wt}^{\mathrm{lac}}$. conditioned medium was to approximately threefold greater than that of $\Delta s r f A^{\text {lacz }}$, in the absence of exogenously added surfactin. Increasing exposure to surfactin increased extracellular $\beta$-galactosidase activity of the $\Delta s r f A^{\text {lacz }}$ strain (Figure $3 \mathbf{A}$ ), reaching levels similar to those in the $\mathrm{wt}^{\mathrm{lac} Z}$ strain after exposure to surfactin for $3 \mathrm{~h}$ (Figure 3A). Increasing surfactin exposure also significantly increased eDNA concentration measured in conditioned medium of the $\Delta s r f A^{\text {lacZ }}$ strain, but had little effect

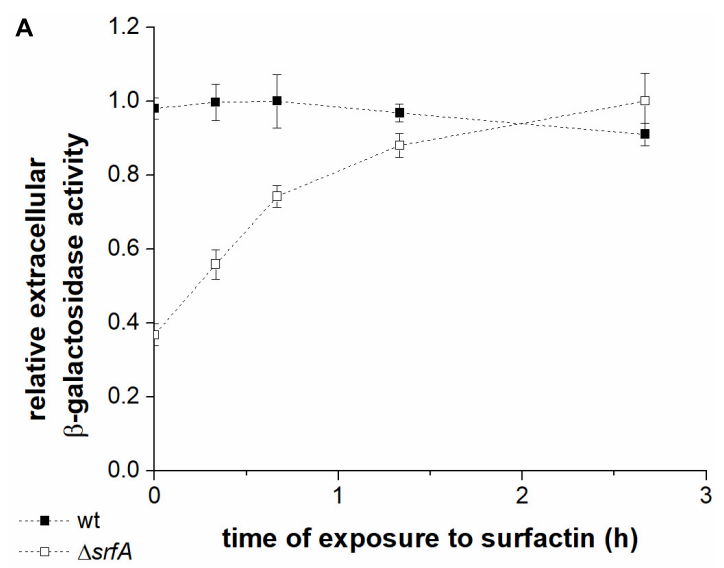

B

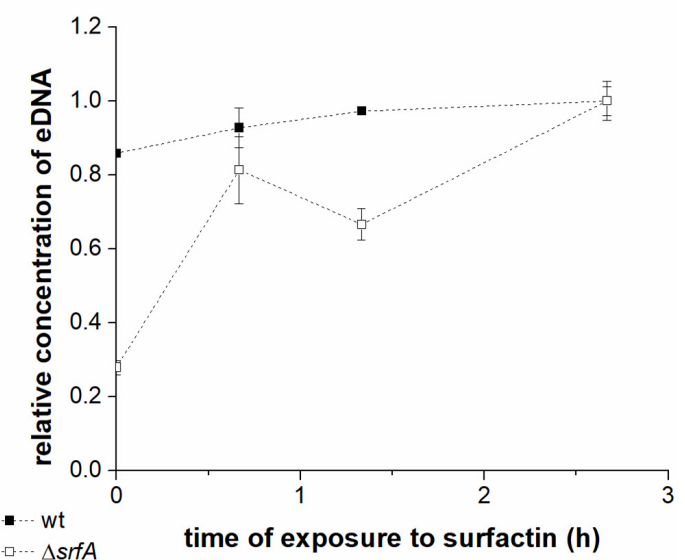

C

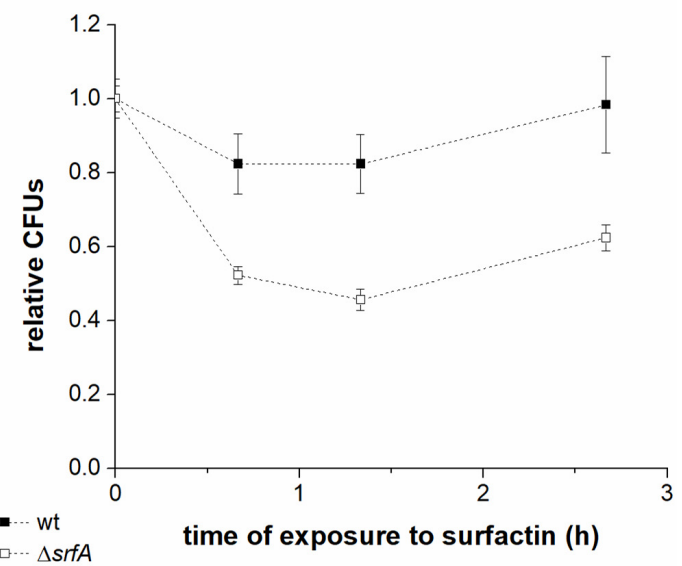

FIGURE 3 | Extracellular $\beta$-galactosidase activity in the conditioned medium (A), DNA released into the medium (B), and colony-forming units (C) in the

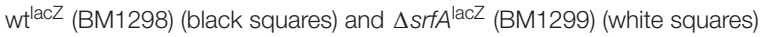
strains after different lengths of exposure to surfactin. Both strains were grown until early stationary phase in $\mathrm{CM}$ medium at $37^{\circ} \mathrm{C}$ and $200 \mathrm{rpm}$ and were then incubated with surfactin $\left(20 \mathrm{\mu g} \mathrm{ml}^{-1}\right)$ for $3 \mathrm{~h}$ at room temperature without shaking. Data were normalized with respect to the highest $\beta$-galactosidase activity (A), eDNA concentration (B), or CFU number (C) of all samples measured for a particular strain, and are presented in relative units. Values are presented as means and standard errors $(n=3)$. 
on eDNA concentration in $\mathrm{wt}^{\mathrm{lacZ}}$ medium (Figure $3 \mathrm{~B}$ ). CFU showed a similar pattern, with twofold greater CFU counts in the $\Delta s r f A^{\text {lacZ }}$ culture than in the wt ${ }^{\text {lacZ }}$ culture, but a subsequent decrease in $\triangle s r f A^{\text {lacZ }} C F U$ within increasing exposure to surfactin (Figure 3C). Together, these results indicated that surfactin causes cell lysis and thus DNA release within the B. subtilis population.

\section{Surfactin-Mediated DNA Release Affects DNA Exchange}

The role of surfactin-mediated DNA release in DNA exchange in co-culture was then examined (Figure 4). This was determined by comparing the transformation frequency of differentially marked wild-type strains (wt $+\mathrm{wt}$ ) and $\operatorname{srfA}$ mutants without or with added surfactin in co-cultures. When comparing transformation frequency of the $\Delta s r f A$ mutant, it is important to note that transposon insertion in the $\Delta s r f A$ mutant does not disrupt the coms gene and, therefore, should not significantly alter transformation frequency (Vollenbroich et al., 1994). This was confirmed by transforming the $\triangle s r f A$ mutant with the wild-type strain chromosomal DNA carrying tetracyclineresistance gene ( $2 \mathrm{~h}$ after the entry into competence state), and the wild-type strain and $\triangle s r f A$ mutant showed comparable transformation frequencies $(p=0.27),\left[(1.17 \pm 0.22) \times 10^{-5}\right]$ and $\left[(0.82 \pm 0.16) \times 10^{-5}\right]$, respectively.

Next co-cultures of $\Delta s r f A^{\text {cat }}\left(\right.$ BM1062) and $\Delta s r f A^{\text {spec }}$ (BM1063) strains were grown in the presence and absence of exogenous surfactin, and the $\mathrm{Cat}^{\mathrm{R}} \mathrm{Spec}^{\mathrm{R}}$ transformants were quantified after co-cultivation for $8 \mathrm{~h}$ in $\mathrm{CM}$ medium. The

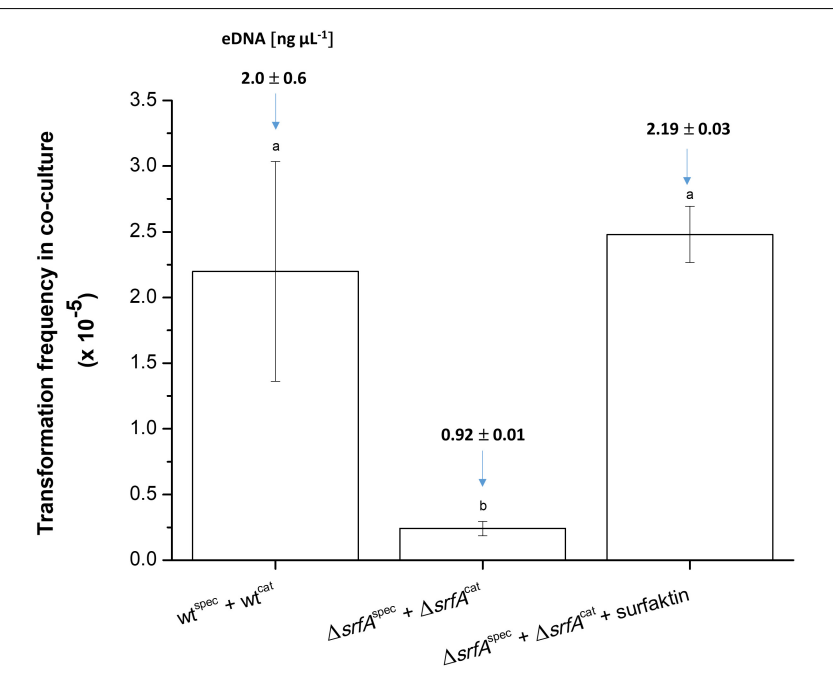

FIGURE 4 | Transformation frequency in co-cultures of $\mathrm{wt}^{\text {cat }}$ $(\mathrm{BM} 1060)+w^{\text {spec }}(\mathrm{BM} 1058)$ and $\Delta s \mathrm{sf}^{\mathrm{cat}}(\mathrm{BM} 1062)+\Delta s r f A^{\text {spec }}(\mathrm{BM} 1063)$ without or with surfactin $\left(20 \mu \mathrm{g} \mathrm{ml}^{-1}\right)$ during growth in $\mathrm{CM}$ medium for $8 \mathrm{~h}$ at $37^{\circ} \mathrm{C}$ and $200 \mathrm{rpm}$. In each experimental variant, the eDNA concentration was determined before the transformation assay and is depicted as the number above each column. The values presented are means and standard errors $(n=3)$. Different letters above the columns indicate a statistically significant difference $(p<0.05)$ between mean values across all strains and treatments (i.e., across all columns). transformation frequency of the $\triangle s r f A$ co-culture increased approximately 10-fold after surfactin addition, reaching a level similar to the wild-type co-culture (Figure 4). eDNA concentration was also measured in these co-cultures before transformation frequency was determined. eDNA concentration of the $\triangle s r f A$ co-culture increased 2.4-fold after surfactin addition, reaching similar eDNA concentration as the wild-type co-culture (Figure 4).

\section{DISCUSSION}

It is well established that QS response regulators function in a pleiotropic manner by simultaneously modulating several different phenotypic traits (Schuster et al., 2003; Comella and Grossman, 2005; Antunes et al., 2007; Dandekar et al., 2012; Majerczyk et al., 2014; Wang et al., 2015). In this study, the role of the quorum-sensing regulated lipopeptide, surfactin, in the DNA release and the consequence of this action on DNA exchange between strains of $B$. subtilis were investigated. We provide evidence that DNA can be exchanged between strains without the external source of eDNA and that this HGT is dependent on eDNA released through surfactin action.

The role of eDNA in horizontal gene transfer has been previously proposed for $B$. subtilis and other naturally competent bacteria such as Neisseria and Streptococcus (Dillard and Seifert, 2001; Steinmoen et al., 2002; Zafra et al., 2012; Veening and Blokesch, 2017). It has been shown that B. subtilis NCIB 3610 strain releases eDNA just before entry into the stationary phase and that the $\triangle s r f A$ mutant shows a defect in eDNA (Zafra et al., 2012), but the study did not indicate a direct role of surfactin in eDNA release. We provide this evidence that the lack of surfactin significantly impairs DNA exchange between $\Delta s r f A^{\text {spec }}$ and $\Delta s r f A^{\text {cat }}$ mutants, while the surfactin addition to the $\mathrm{CM}$ medium fully restores the transformation frequency of the $\Delta$ srfA mutants. Although it could be argued that the $\operatorname{srfA}$ mutant may be defective in transformation also due to ComS deficiency, we showed that this is not the case as the $\Delta s r f A$ mutant used in this study was still transformable by externally added DNA to comparable levels as the wild-type strain. Moreover, surfactin addition to the co-culture of two $s r f A$ mutants restored the transformation to the wild-type levels, providing a direct evidence that this lipopeptide mediates DNA exchange, which can be abolished by DNase.

We provided here evidence that surfactin contributes to horizontal gene transfer by inducing cell lysis in a fraction of cells. It is known that surfactin producers are protected against surfactin due to resistance provided by efflux pump SwrC (YerP), which is responsible for surfactin secretion and self-resistance to surfactin (Tsuge et al., 2001). A self-tolerance against the membrane active surfactin might also be provided by the modification of the phospholipid content in the membrane of the B. subtilis cells (Uttlová et al., 2016). Although all cells activate $\operatorname{srf} A$ operon, over time, they show a broad heterogeneity in srfA expression levels (Miras and Dubnau, 2016; Dogsa et al., 2021). Moreover, although specific subpopulation undergoing lysis has not been detected, we have recently 
reported that $s r f A$ operon is already activated during the early to mid-exponential phase (Dogsa et al., 2021), between 2.5 and $3 \mathrm{~h}$ of growth, where strong heterogeneity in srfA expression is evident with a small population showing very low fluorescence of srfA-cfp reporter (Dogsa et al., 2021). Therefore, cells expressing srfA operon at very low levels might be the potential targets of surfactin-mediated lysis. We have previously observed that the membrane permeability changes during the planktonic growth of B. subtilis-PS-216 culture with the highest proportion of "damaged" cells (approximately 25-30\%) detected around $4 \mathrm{~h}$ of growth (late exponential phase) (Oslizlo et al., 2014). This number dropped to only $10 \%$ in surfactin non-producers (Oslizlo et al., 2014). Although it remains to be proven whether this change in cell permeability is linked to surfactin-mediated lysis and eDNA release, this observation is consistent with the hypothesis that surfactin increases a proportion of cells with compromised membrane integrity (Deleu et al., 2013). This phenotypic change in the membrane is especially interesting because it coincides in time with the induction of the master regulator ComK and the transition to K-state (Miras and Dubnau, 2016) in 10-20\% of cells (Maamar and Dubnau, 2005; Miras and Dubnau, 2016; Maier, 2020). These cells are known to be resistant to antibiotics, most probably due to growth arrest (Nester and Stocker, 1963; Engelmoer and Rozen, 2011; Yüksel et al., 2016), and therefore not targeted for surfactin lysis.

Surfactin has a broad spectrum of antimicrobial activity, and it can also lyse other Bacilli and non-Bacilli (Sharma et al., 2020), but the frequency of homologous recombination decreases sharply with the level of relatedness between the donor DNA and recipient strain's genome (Majewski and Cohan, 1999). Therefore, we suggest that the action of surfactin may be more important for horizontal gene transfer between genetically highly related B. subtills strains or even within clonal populations and not between distantly related Bacillus strains. We have recently shown that the DNA exchange also occurs on agar surfaces at the meeting point of two swarms (Stefanic et al., 2021). However, it needs to be tested whether surfactin, which is essential for surface spreading, also contributes to eDNA release during swarming.

\section{REFERENCES}

Albano, M., Hahn, J., and Dubnau, D. (1987). Expression of competence genes in Bacillus subtilis. J. Bacteriol. 169, 3110-3117. doi: 10.1128/jb.169.7.3110-3117. 1987

Aleti, G., Lehner, S., Bacher, M., Compant, S., Nikolic, B., Plesko, M., et al. (2016). Surfactin variants mediate species-specific biofilm formation and root colonization in Bacillus. Environ. Microbiol. 18, 2634-2645. doi: 10.1111/14622920.13405

Antunes, L. C. M., Schaefer, A. L., Ferreira, R. B. R., Qin, N., Stevens, A. M., Ruby, E. G., et al. (2007). Transcriptome analysis of the Vibrio fischeri LuxR-LuxI regulon. J. Bacteriol. 189, 8387-8391. doi: 10.1128/JB.00736-07

Bais, H. P., Fall, R., and Vivanco, J. R. (2004). Biocontrol of Bacillus subtilis against infection of Arabidopsis roots by Pseudomonas syringae is facilitated by biofilm formation and surfactin production. Plant Physiol. 134, 307-319. doi: $10.1104 /$ pp.103.028712

Berka, R. M., Hahn, J., Albano, M., Draskovic, I., Persuh, M., Cui, X., et al. (2002). Microarray analysis of the Bacillus subtilis K-state: genome-wide expression changes dependent on ComK. Mol. Microbiol. 43, 1331-1345. doi: 10.1046/j. 1365-2958.2002.02833.x
To conclude, we have demonstrated that surfactin contributes to horizontal gene transfer between the two almost identical populations of $B$. subtilis by inducing cell lysis in a fraction of cells. eDNA released from lysed cells then serves as the source of new genetic traits for nearby competent cells or for DNA repair, if exchange occurs within clonal population. Therefore, surfactin is linked to horizontal gene transfer at the level of its operon, which embeds ComS and, as a pore-forming lipopeptide, that contributes to eDNA pool.

\section{DATA AVAILABILITY STATEMENT}

The original contributions presented in the study are included in the article/supplementary material, further inquiries can be directed to the corresponding author/s.

\section{AUTHOR CONTRIBUTIONS}

$\mathrm{TD}, \mathrm{AD}$, and $\mathrm{IM}-\mathrm{M}$ conceived and designed the experiments. $\mathrm{TD}, \mathrm{AD}, \mathrm{MS}$, and PS performed the experiments. TD, AD, MS, PS, and ID analyzed the data. TD, AD, PS, and IM-M wrote the manuscript. All authors contributed to the final version of the manuscript.

\section{FUNDING}

The work has been funded by the Slovenian Research Agency ARRS program grant No. P4-0116 and project grants J4-1175, J4-8228, and J4-9302.

\section{ACKNOWLEDGMENTS}

We thank Ákos T. Kovács for constructive discussions and James I. Prosser for helping us improve the manuscript.

Comella, N., and Grossman, A. D. (2005). Conservation of genes and processes controlled by the quorum response in bacteria: characterization of genes controlled by the quorum-sensing transcription factor ComA in Bacillus subtilis. Mol. Microbiol. 57, 1159-1174. doi: 10.1111/j.1365-2958.2005. 04749.x

Dandekar, A. A., Chugani, S., and Greenberg, E. P. (2012). Bacterial quorum sensing and metabolic incentives to cooperate. Science 338, 264-266. doi: 10. 1126/science.1227289

Deleu, M., Lorent, J., Lins, L., Brasseur, R., Braun, N., El Kirat, K., et al. (2013). Effects of surfactin on membrane models displaying lipid phase separation. Biochim. Biophys. Acta Biomembr. 1828, 801-815. doi: 10.1016/j.bbamem.2012. 11.007

Dillard, J. P., and Seifert, H. S. (2001). A variable genetic island specific for Neisseria gonorrhoeae is involved in providing DNA for natural transformation and is found more often in disseminated infection isolates. Mol. Microbiol. 41, 263-277. doi: 10.1046/j.1365-2958.2001.02520.x

Dogsa, I., Spacapan, M., Dragoš, A., Danevčič, T., Pandur, Ž, and Mandic-Mulec, I. (2021). Peptide signaling without feedback in signal production operates as a true quorum sensing communication system in Bacillus subtilis. Commun. Biol. 4:58. doi: 10.1038/s42003-020-01553-5 
Donovan, W., Zheng, L. B., Sandman, K., and Losick, R. (1987). Genes encoding spore coat polypeptides from Bacillus subtilis. J. Mol. Biol. 196, 1-10. doi: 10.1016/0022-2836(87)90506-7

D’Souza, C., Nakano, M. M., and Zuber, P. (1994). Identification of comS, a gene of the $\operatorname{srfA}$ operon that regulates the establishment of genetic competence in Bacillus subtilis. Proc. Natl. Acad. Sci. U. S. A. 91, 9397-9401. doi: 10.1073/pnas. 91.20.9397

Dubnau, D. (1991). Genetic competence in Bacillus subtilis. Microbiol. Rev. 55, 395-424. doi: 10.1128/mr.55.3.395-424.1991

Engelmoer, D. J. P., and Rozen, D. E. (2011). Competence increases survival during stress in Streptococcus pneumoniae. Evolution 65, 3475-3485. doi: 10.1111/j. 1558-5646.2011.01402.x

Grau, R. R., de Oña, P., Kunett, M., Leñini, C., Gallegos-Monterrosa, R., Mhatre, E., et al. (2015). A duo of potassium-responsive histidine kinases govern the multicellular destiny of Bacillus subtilis. mBio 6, e00581-15. doi: 10.1128/mBio. 00581- 15

Hamoen, L. W., Venema, G., and Kuipers, O. P. (2003). Controlling competence in Bacillus subtilis: shared use of regulators. Microbiology 149, 9-17. doi: 10.1099/ mic.0.26003-0

Ibáñez de Aldecoa, A. L., Zafra, O., and González-Pastor, J. E. (2017). Mechanisms and regulation of extracellular DNA release and its biological roles in microbial communities. Front. Microbiol. 8:1390. doi: 10.3389/fmicb.2017. 01390

Kearns, D. B., and Losick, R. (2003). Swarming motility in undomesticated Bacillus subtilis. Mol. Microbiol. 49, 581-590. doi: 10.1046/j.1365-2958.2003.03584.x

Kinsinger, R. F., Shirk, M. C., and Fall, R. (2003). Rapid surface motility in Bacillus subtilis is dependent on extracellular surfactin and potassium ion. J. Bacteriol. 185, 5627-5631. doi: 10.1128/JB.185.18.5627-5631.2003

Liu, W. T., Yang, Y. L., Xu, Y., Lamsa, A., Haste, N. M., Yang, J. Y., et al. (2010). Imaging mass spectrometry of intraspecies metabolic exchange revealed the cannibalistic factors of Bacillus subtilis. Proc. Natl. Acad. Sci. U. S. A. 107, 16286-16290. doi: 10.1073/pnas.1008368107

Maamar, H., and Dubnau, D. (2005). Bistability in the Bacillus subtilis K-state (competence) system requires a positive feedback loop. Mol. Microbiol. 56, 615-624. doi: 10.1111/j.1365-2958.2005.04592.x

Magnuson, R., Solomon, J., and Grossman, A. D. (1994). Biochemical and genetic characterization of a competence pheromone from B. subtilis. Cell 77, 207-216. doi: 10.1016/0092-8674(94)90313-1

Maier, B. (2020). Competence and Transformation in Bacillus subtilis. Curr. Issues Mol. Biol. 37, 57-76. doi: 10.21775/cimb.037.057

Majerczyk, C., Bittnacher, M., Jacobs, M., Armour, C. D., Radey, M., Schneider, E., et al. (2014). Global analysis of the Burkholderia thailandensis quorum sensing-controlled regulon. J. Bacteriol. 196, 1412-1424. doi: 10.1128/JB. 01405-13

Majewski, J., and Cohan, F. M. (1999). DNA sequence similarity requirements for interspecific recombination in Bacillus. Genetics 153, 1525-1533.

Meijer, W. J. J., van der Lelie, D., Venema, G., and Bron, S. (1995). Effects of the generation of single-stranded DNA on the maintenance of plasmid pMV158 and derivatives in different Bacillus subtilis strains. Plasmid 33, 79-89. doi: $10.1006 /$ plas. 1995.1010

Miras, M., and Dubnau, D. (2016). A DegU-P and DegQ-dependent regulatory pathway for the K-state in Bacillus subtilis. Front. Microbiol. 7:1868. doi: 10. 3389/fmicb.2016.01868

Nakano, M. M., Magnuson, R., Myers, A., Curry, J., Grossman, A. D., and Zuber, P. (1991). srfA is an operon required for surfactin production, competence development, and efficient sporulation in Bacillus subtilis. J. Bacteriol. 173, 1770-1778. doi: 10.1128/jb.173.5.1770-1778.1991

Nakano, M. M., Marahiel, M. A., and Zuber, P. (1988). Identification of a genetic locus required for biosynthesis of the lipopeptide antibiotic surfactin in Bacillus subtilis. J. Bacteriol. 170, 5662-5668. doi: 10.1128/jb.170.12.5662-5668.1988

Nester, E. W., and Stocker, B. A. D. (1963). Biosynthetic latency in early stages of deoxyribonucleic acid transformation in Bacillus subtilis. J. Bacteriol. 86, 785-796. doi: 10.1128/jb.86.4.785-796.1963

Oslizlo, A., Stefanic, P., Dogsa, I., and Mandic-Mulec, I. (2014). Private link between signal and response in Bacillus subtilis quorum sensing. Proc. Natl. Acad. Sci. U. S. A. 111, 1586-1591. doi: 10.1073/pnas.1316283111

Roggiani, M., and Dubnau, D. (1993). ComA, a phosphorylated response regulator protein of Bacillus subtilis, binds to the promoter region of srfA. J. Bacteriol. 175, 3182-3187. doi: 10.1128/jb.175.10.3182-3187.1993
Schuster, M., Lostroh, C. P., Ogi, T., and Greenberg, E. P. (2003). Identification, timing, and signal specificity of Pseudomonas aeruginosa quorum-controlled genes: a transcriptome analysis. J. Bacteriol. 185, 2066-2079. doi: 10.1128/JB. 185.7.2066-2079.2003

Sharma, D., Singh, S. S., Baindara, P., Sharma, S., Khatri, N., Grover, V., et al. (2020). Surfactin like broad spectrum antimicrobial lipopeptide co-produced with sublancin from Bacillus subtilis strain A52: dual reservoir of bioactives. Front. Microbiol. 11:1167. doi: 10.3389/fmicb.2020.01167

Stefanic, P., Belcijan, K., Kraigher, B., Kostanjšek, R., Nesme, J., Madsen, J., et al. (2021). Kin discrimination promotes horizontal gene transfer between unrelated strains in Bacillus subtilis. bioRxiv 756569. doi: 10.1101/756569

Stefanic, P., Kraigher, B., Lyons, N. A., Kolter, R., and Mandic-Mulec, I. (2015). Kin discrimination between sympatric Bacillus subtilis isolates. Proc. Natl. Acad. Sci. U. S. A. 112, 14042-14047. doi: 10.1073/pnas.1512671112

Stefanic, P., and Mandic-Mulec, I. (2009). Social interactions and distribution of Bacillus subtilis pherotypes at microscale. J. Bacteriol. 191, 1756-1764. doi: 10.1128/JB.01290-08

Steinmoen, H., Knutsen, E., and Havarstein, L. S. (2002). Induction of natural competence in Streptococcus pneumoniae triggers lysis and DNA release from a subfraction of the cell population. Proc. Natl. Acad. Sci. U. S. A. 99, 7681-7686. doi: 10.1073/pnas.112464599

Tsuge, K., Ohata, Y., and Shoda, M. (2001). Gene yerP, involved in surfactin selfresistance in Bacillus subtilis. Antimicrob. Agents Chemother. 45, 3566-3573. doi: 10.1128/AAC.45.12.3566-3573.2001

Turgay, J., Hahn, J., Burghoorn, J., and Dubnau, D. (1998). Competence in Bacillus subtilis is controlled by regulated proteolysis of a transcription factor. EMBO J. 17, 6730-6738. doi: 10.1093/emboj/17.22.6730

Uttlová, P., Pinkas, D., Bechyòková, O., Fišer, R., Svobodová, J., and Seydlová, G. (2016). Bacillus subtilis alters the proportion of major membrane phospholipids in response to surfactin exposure. Biochim. Biophys. Acta Biomembr. 1858, 2965-2971. doi: 10.1016/j.bbamem.2016.09.006

van Gestel, J., Vlamakis, H., and Kolter, R. (2015). From cell differentiation to cell collectives: Bacillus subtilis uses division of labor to migrate. PLoS Biol. 13:e1002141. doi: 10.1371/journal.pbio.1002141

Veening, J. W., and Blokesch, M. (2017). Interbacterial predation as a strategy for DNA acquisition in naturally competent bacteria. Nat. Rev. Microbiol. 10, 621-629. doi: 10.1038/nrmicro.2017.66

Vollenbroich, D., Mehta, N., Zuber, P., Valter, J., and Kamp, R. M. (1994). Analysis of surfactin synthetase subunits in srfA mutants of Bacillus subtilis OKB105. J. Bacteriol. 176, 395-400. doi: 10.1128/jb.176.2.395-400.1994

Wang, M., Schaefer, A. L., Dandekar, A. A., and Greenberg, E. P. (2015). Quorum sensing and policing of Pseudomonas aeruginosa social cheaters. Proc. Natl. Acad. Sci. U. S. A. 17, 2187-2191. doi: 10.1073/pnas.1500704112

Weinrauch, Y., Penchev, R., Dubnau, E., Smith, I., and Dubnau, D. (1990). A Bacillus subtilis regulatory gene product for genetic competence and sporulation resembles sensor protein members of the bacterial two-component signal-transduction systems. Gene. Dev. 4, 860-872. doi: 10.1101/gad.4.5.860

Yuan, L., Zhang, S., Wang, Y., Li, Y., Wang, X., and Yang, Q. (2018). Surfactin inhibits membrane fusion during invasion of epithelial cells by enveloped viruses. J. Virol. 92, e00809-18. doi: 10.1128/JVI.00809-18

Yüksel, M., Power, J. J., Ribbe, J., Volkmann, T., and Maier, B. (2016). Fitness Trade-Offs in Competence Differentiation of Bacillus subtilis. Front. Microbiol. 7:888. doi: 10.3389/fmicb.2016.00888

Zafra, O., Lamprecht-Grandio, M., González de Figueras, C., and González-Pastor, J. E. (2012). Extracellular DNA release by undomesticated Bacillus subtilis is regulated by early competence. PLoS One 7:e48716. doi: 10.1371/journal.pone. 0048716

Conflict of Interest: The authors declare that the research was conducted in the absence of any commercial or financial relationships that could be construed as a potential conflict of interest.

Copyright (c) 2021 Danevčič, Dragoš, Spacapan, Stefanic, Dogsa and Mandic-Mulec. This is an open-access article distributed under the terms of the Creative Commons Attribution License (CC BY). The use, distribution or reproduction in other forums is permitted, provided the original author(s) and the copyright owner(s) are credited and that the original publication in this journal is cited, in accordance with accepted academic practice. No use, distribution or reproduction is permitted which does not comply with these terms. 